\title{
Editorials
}

\section{Reducing unwarranted variations in healthcare in the English NHS}

BMJ 2011; 342 doi: http://dx.doi.org/10.1136/bmj.d1849 (Published 22 March 2011) Cite this as: BMJ 2011;342:d1849

- Article

- Related content

- Metrics

- Responses

- Peer review

-

Nicholas Mays, professor of health policy

\section{Author affiliations}

nicholas.mays@Ishtm.ac.uk

Information in the NHS atlas is illuminating but changing practice is what matters

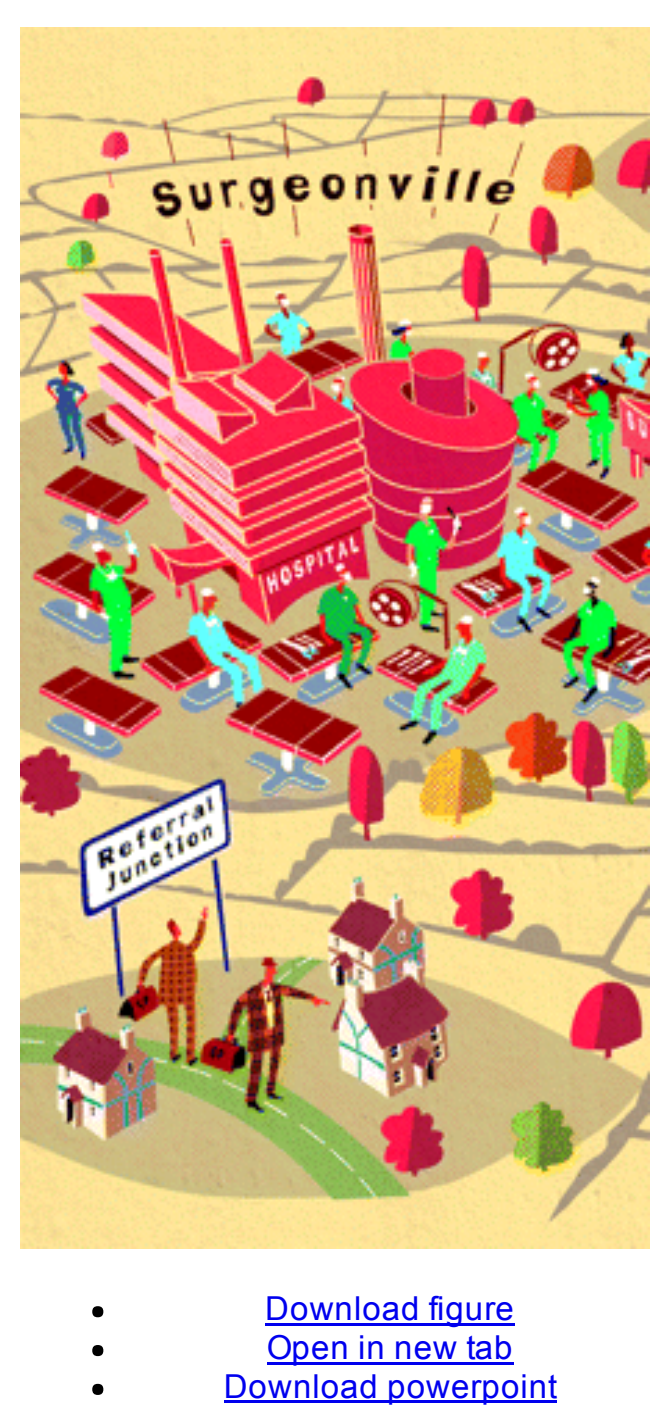

"Paul Boston" 
Late last year, The NHS Atlas of Variation in Healthcare was published by the Department of Health,1 inspired by the American Dartmouth Atlas of Health Care.2 In the linked Analysis article (doi:10.1136/bmj.d1513), John Wennberg, the "father" of the Dartmouth atlas, writes approvingly of the NHS atlas. 3

For a wide range of selected specialties identified by Department of Health national clinical directors, it documents variations by primary care trust in treatment and investigation rates, care processes, resource use, expenditure, and outcomes. The idea behind the atlas is that publicising these variations and giving commissioners and providers tools to analyse and investigate them will help reduce avoidable differences between areas, thereby improving the effectiveness and efficiency of the English NHS.

Like the Dartmouth atlas, the NHS atlas shows large (typically twofold to fivefold, and often much higher) unexplained variations on many indicators, although the differences between the top and the bottom are generally not as stark as in the United States. A commentary by Gert Westert and Marjan Faber (doi:10.1136/bmj.d1429) shows a similar pattern of unwarranted (unrelated to patients' needs or preferences) variation in the Netherlands, which until recently, like England, had a largely planned healthcare system with much more modest variation in healthcare supply than in the US.4 However, questions about such exercises remain.

Firstly, how should variations be interpreted? Using research on variations in outcome in relation to variations in inputs and processes of care, Wennberg concludes that, at least in the US, regions and hospitals with high rates of treatment or surgery produce no better results in terms of survival than low rate regions and hospitals. For England, he is more cautious given its historically lower overall level of spending and real resources, but he says that better integration between primary and secondary care would result in similar savings to those predicted for the US.

Secondly, how does the documentation of variations help with their solutions, given that these variations are well known? Wennberg suggests that researchers and clinicians on both sides of the Atlantic need to study and experiment with chronic care to develop better clinical pathways and link primary and secondary care into organised systems. Although this approach may be sensible it is not clear how it is justified from the analyses in the NHS atlas. Many of the variations documented (such as proportion of people with diabetes receiving nine approved care processes or proportion of patients admitted to hospital after a stroke spending $90 \%$ of their time on a stroke unit) relate to decisions taken by primary or secondary care clinicians alone and not to a lack of coordination.

Thirdly, why are variations so deeply embedded? Wennberg states that research on practice variation over many decades has established the value of performance monitoring and feedback in promoting change in clinical practice. This may be true but its impact has been modest. Perhaps it will make a difference that the evidence on unwarranted variations has been unified and published at national level under the auspices of the NHS in this atlas, rather than in separate publications and analyses spread across different clinical specialties. However, the crucial point will be how the atlas is used. As clinically led organisations, the new general practitioner commissioning consortiums planned as part of the current NHS reforms may be better placed than primary care trusts to identify and reduce unwarranted variations. 5 Consortiums may have more incentive to keep within their tight budgets because they can invest savings in services provided by their constituent general practices. But whether this will play out in practice remains to be seen. 
Other current changes to the healthcare system in England are moving things in the opposite direction. For example, the Audit Commission, which used to publish rigorous detailed comparisons of the performance of specific NHS services with a strong emphasis on geographical variations, is being abolished. The emphasis on localism in current policy rhetoric, with more new commissioning organisations contracting with a widening range of "any willing" providers, 6 might encourage more not less variation and hamper the primary-secondary care coordination for chronic conditions advocated by Wennberg.

Perhaps most worrying for the ability of the English NHS to collect and link input, activity, and outcome data to particular populations is that the new commissioning consortiums will be federations of independent practices without geographically defined populations. Thus there will always be some ambiguity about the denominator when measures of their performance are being calculated and compared.

\section{Notes}

Cite this as: $B M J$ 2011;342:d1849

\section{Footnotes}

\section{- Analysis, doi:10.1136/bmj.d1513}

- Analysis, doi:10.1136/bmj.d1429

- Competing interests: The author has completed the Unified Competing Interest form at www.icmje.org/coi_disclosure.pdf (available on request from the corresponding author) and declares: no support from any organisation for the submitted work; no financial relationships with any organisations that might have an interest in the submitted work in the previous three years; no other relationships or activities that could appear to have influenced the submitted work.

- Provenance and peer review: Commissioned; not externally peer reviewed.

\section{References}

1. $\downarrow$ QIPP/Right Care. The NHS atlas of variation in healthcare. 2010. www.rightcare.nhs. uk/atlas/.

2. $\downarrow$ Dartmouth Atlas of Health Care. www.dartmouthatlas.org/.

3. Wennberg JE. Time to tackle unwarranted variations in practice. BMJ2011;342:d1513. FREE Full Text

4. $\downarrow$ Westert GP, Faber M. Commentary: the Dutch approach to unwarranted medical practice variation. BMJ 2011;342:d1429. FREE Full Text

5. $\downarrow$ Department of Health. Equity and excellence: liberating the NHS. 2010. www.dh.gov.uk/en/Publicationsandstatistics/Publications/PublicationsPolicyAndGuidance/DH 117353.

6. $\downarrow$ Department of Health. Liberating the NHS: legislative framework and next steps. 2010. www.dh.gov.uk/en/Publicationsandstatistics/Publications/PublicationsPolicyAndGuidance/DH 122661. 